\title{
Patient Positioning in Shoulder Arthroscopy: Which is Best?
}

\author{
Jorge Rojas $^{10}$ Filippo Familiari2 ${ }^{20}$ \\ Edward G. McFarland ${ }^{1} \odot$ \\ ${ }^{1}$ Division of Shoulder Surgery, Department of Orthopaedic Surgery, \\ The Johns Hopkins University, Baltimore, Maryland, United States \\ ${ }^{2}$ Department of Orthopaedic and Trauma Surgery, "Villa del Sole" \\ Clinic, Catanzaro, Italy \\ ${ }^{3}$ Department of Orthopaedic and Trauma Surgery, \\ Campus Bio-Medico University, Rome, Italy
}

Joints 2019;7:46-55
Address for correspondence Edward G. McFarland, MD, Division of Shoulder and Elbow Surgery, Department of Orthopaedic Surgery, The Johns Hopkins University, 10753 Falls Road, Pavilion II, Suite 215, Lutherville, Maryland 21093, United States (e-mail: emacfarl1@jhmi.edu).
Abstract
Keywords
- shoulder
- arthroscopy
- positioning
- complications
- beach chair
- lateral decubitus
- stroke
- neuropraxia

When performing diagnostic and surgical arthroscopic procedures on the shoulder, the importance of patient positioning cannot be understated. The optimum patient positioning for shoulder arthroscopy should enhance intraoperative joint visualization and surgical accessibility while minimizing potential perioperative risk to the patient. Most shoulder arthroscopy procedures can be reliably performed with the patient either in the lateral decubitus (LD) or beach chair (BC) position. Although patient positioning for shoulder arthroscopy has been subject of controversy, there is no conclusive evidence to suggest superiority of one position versus another. Each position offers advantages and disadvantages and surgeon's experience and training are pivotal on selecting one position versus another. Regardless of the position, a proper positioning of the patient should provide adequate access to the joint while minimizing complications. The purpose of this review is to summarize setup and technical aspects, the advantages and disadvantages, and the possible complications of the LD and BC positions in shoulder arthroscopy.

\section{Introduction}

Patient positioning is a critical step in surgical preparation for shoulder arthroscopy. In addition to providing optimal visualization and access to the shoulder, careful positioning can minimize the risk of perioperative complications. Most arthroscopic shoulder procedures can be reliably performed either in the lateral decubitus (LD) or beach chair (BC) position. However, the advocates of one position over another differ over the intraoperative visualization and joint accessibility, ease and cost of the setup, ease of conversion to an open procedure, and complication types and rates. These complications include consequences of physiological changes affecting cerebral perfusion and soft tissue complications due to pressure or traction, specifically skin pressure injuries and nerve or vascular injuries.
In the absence of conclusive evidence that indicates superiority of one position versus another, ${ }^{1}$ surgeon's experience, training and level of comfort are pivotal on the selection of patient positioning. Regardless of the position, optimal shoulder arthroscopy positioning must include three components to achieve safe and successful patient positioning: knowledge, planning, and teamwork. ${ }^{2}$ Surgeons, anesthesiologist, and operating room staff must know and be familiar with the technique, safety principles, physiological changes, and possible risks associated with the position utilized. Additionally, careful planning that involves communication and teamwork is the key to anticipate specific patient challenges (e.g., obese patients, rheumatoid arthritis patients, previous arthroplasties) and to prevent possible complications. received

May 26, 2018

accepted

August 6, 2019

published online

October 11, 2019
DOI https://doi.org/

$10.1055 / \mathrm{s}-0039-1697606$. ISSN 2282-4324.
Copyright $\odot 2019$ Georg Thieme Verlag License terms

KG Stuttgart · New York

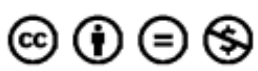


This article reviews the advantages and disadvantages, setup and technical aspects, physiological changes, and possible complications of the LD and BC positions in shoulder arthroscopy. This review will emphasize recommendations for correct positioning and review preventive measures to achieve a safe, reliable, and reproducible technique for patient positioning in both the $\mathrm{BC}$ and $\mathrm{LD}$ positions.

\section{Lateral Decubitus Position}

The LD position with the arm held in traction parallel to its long axis is the classical positioning for shoulder arthroscopy (-Fig. 1). The main advantage of this position is that with traction on the arm there is a good visualization of the joint and there is an adequate working space within the glenohumeral joint. ${ }^{1,3,4}$ Specifically, the LD allows good visualization and access to the inferior and posterior labrum, inferior capsule, subacromial space, and articular side of the rotator cuff. ${ }^{5}$ Other advantages reported in the literature include that the operating room table or patient's head is not in the way of working for posterior and superior shoulder, ${ }^{3}$ increased comfort and decreased fatigue for the surgeons while operating with arms at side (as opposed to with their arms in an abducted position as in the BC position), ${ }^{5}$ decreased risk of hypotensive-bradycardic episodes, ${ }^{4}$ lower incidence of cerebral desaturation events compared with the $\mathrm{BC}$ position $^{6,7}$ and that bubbles created by electrocautery move laterally out of view. ${ }^{3}$ The main disadvantages of the LD position reported in the literature include the use of traction which has been implicated in postoperative neurapraxias, the nonanatomical orientation of the joint, the need to lift and turn the patient, ${ }^{8}$ the tendency for the traction device to place the patient's arm in internal rotation, ${ }^{8}$ the difficulty manipulating the operative arm when in applied traction, ${ }^{3}$ the need to reach around the arm for anterior portal, ${ }^{3}$ the need for general endotracheal anesthesia as patients might not tolerate regional anesthesia and the risk of airway obstruction, ${ }^{3}$ an increased risk of injury to axillary and musculocutaneous nerves when placing an anteroinferior

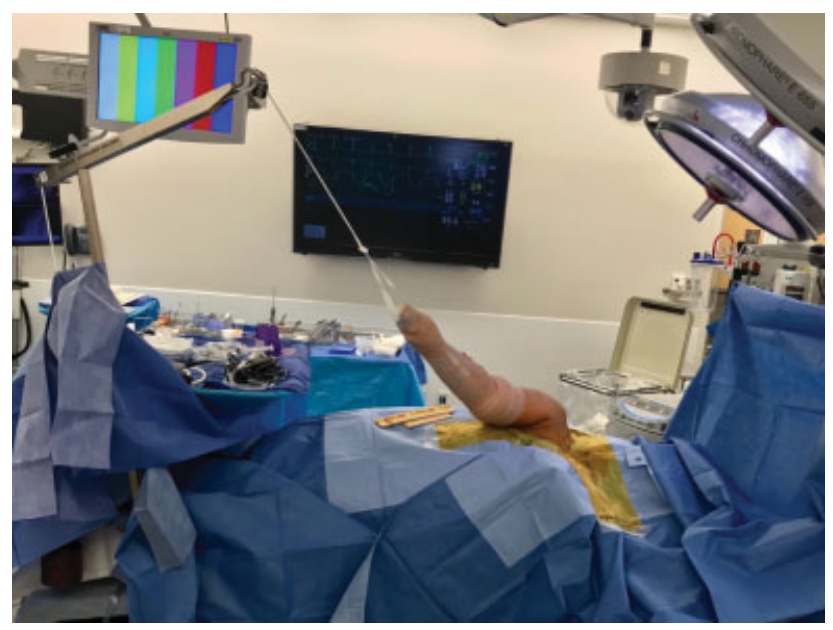

Fig. 1 Patient prepared and draped for shoulder arthroscopy in the lateral decubitus position.
Table 1 Key steps for patient positioning in the lateral decubitus position

1. Plan and anticipate specific patient challenges for positioning.

2. Ensure that all required equipment setup is available and properly working.

3. Level the upper border of the bean bag with the patient's upper thorax yet not protrude into the axilla.

4. Turn the patient onto the nonoperative side.

5. The head is stabilized by the anesthesia team during positioning.

6. Ensure a neutral position of the head during the procedure to prevent cervical strain. Folded sheets under the padded surface may be used to level the head.

7. Place the axillary roll just inferior to the axilla (two to three finger-breadths) adjacent to the chest wall, not into the axilla.

8. Carefully position the contralateral arm on a padded arm board at 90 degrees of abduction

9. Place a pillow under the bottom knee and between the knees to avoid pressure injuries.

10. Check and avoid any undue pressure zones in the genitals, areola, or bony prominences from the bean bag or the rigid post system.

11. Secure the patient to the table using a safety strap. Heavy tape may be used to maintain the position during the surgical procedure.

12. Place the arm into the traction/holding device, and apply the traction.

13. Be aware when applying traction to avoid neurological damage.

portal, ${ }^{9}$ and the possible need to repeat the skin preparation and draping if conversion to an open procedure is necessary. ${ }^{3}$

\section{LD Position Setup}

A summary of key steps for LD patient positioning is provided in - Table 1.

The essential equipment required in the setup of the LD position includes a device to stabilize the patient in a lateral position, padding for the bony prominences, and a shoulder traction device. The stabilization device to maintain the $\mathrm{LD}$ position may be a vacuum bean bag (e.g., Olympic Vac-Pac System, Natus Medical, San Carlos, California, United States) that creates a firm boundary for patient's torso or a rigid post system (e.g., pegboard). One advantage of the bean bag is that allows to set a modified LD position in which the patient's torso leans posteriorly 30 to 40 degrees. This modification to the direct LD position was introduced by Gross and Fitzgibbons ${ }^{10}$ in 1985 (-Fig. 2) based upon the observation that the scapula rests on the thorax at a 30 to 40 -degree angle with the frontal plane of the patient. This repositioning puts the plane of the shoulder joint in a horizontal position, making the arthroscopy more natural and comfortable. Additionally, this posteriorly leaned position or "floppy lateral" position, ${ }^{5}$ has been proposed as an easier position than the direct LD in case of conversion to an open procedure since the bean bag may be flattened and the patient can be gently leaned backward in a safe position. This also may save time and supplies by obviating the need for a new drape and prep of the shoulder and extremity. 


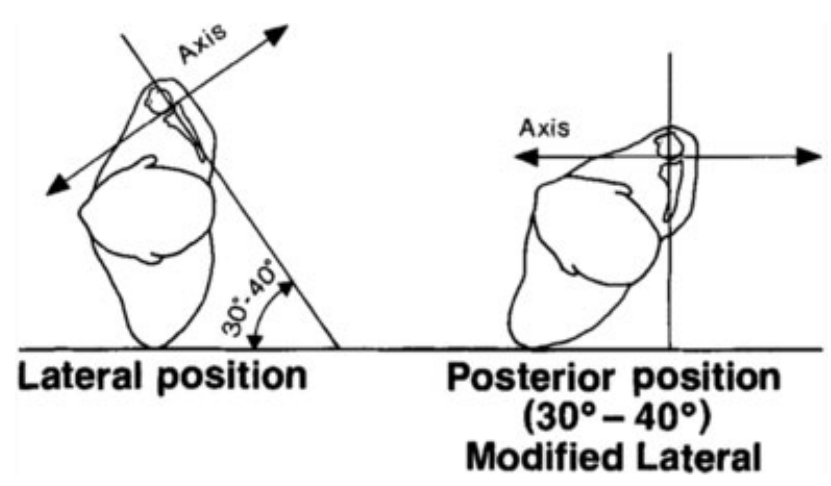

Fig. 2 Modified lateral position places shoulder joint in a horizontal plane (Reproduced with permission from Gross and Fitzgibbons ${ }^{10}$ ).

Disadvantages of the bean bag are the need for suction for a secure fit and the bag may lose rigidity over time if damaged. ${ }^{1}$ Leaks in the bean bag cannot be easily repaired and require that other methods may be necessary if other bean bags are not available. Factors that might favor the use of the rigid post system are that no suction is required, intraoperative patient position changes are less likely, and patient size is less of an issue. ${ }^{1}$

Traction devices for use in the LD position hold the arm in a slightly abducted and flexed position. There are several commercially available traction devices and can be categorized as static pulley devices, adjustable pneumatic or mechanical devices. ${ }^{1}$ Most of the pneumatic or mechanical arm holding devices commonly used with the BC position (e.g., Spider 2 Limb Positioner, Smith and Nephew, Andover, Massachusetts, United States) can be utilized for the LD position (-Fig. 3). Static pulley devices rely on simple traction and are typically adjusted with the application of weight (e.g., Acufex Shoulder Holder, Smith and Nephew, Andover, Massachusetts, United States; Shoulder Traction Device, Biomet Orthopedics, Warsaw, Indiana, United States). Although static pulley devices allow more limited arm motion and positions than those achieved with arm-holding pneumatic devices, they have a decreased cost and a relatively simple setup. ${ }^{1}$ Some static systems permit rotational adjustment of the arm (e.g., Shoulder Distraction System/STaR sleeve (Arthrex, Naples, Florida, United States), but the advantage of this feature is unclear.

\section{LD Position Physiological Effects}

In the LD position, especially if reverse Trendelenburg position is used, blood may pool in the dependent lower extremities, causing reduced venous return to the central circulation followed by hypotension. ${ }^{11}$ However, hypotensive anesthesia during orthopedic procedures has been shown to be a safe and effective anesthetic technique for reducing operative blood losses and helping to maintain a clear surgical field. ${ }^{12,13}$ Morrison et $\mathrm{al}^{14}$ indicated that a safe and clear operative field can be achieved by a pressure difference of $49 \mathrm{~mm} \mathrm{Hg}$ between the systolic blood pressure and the pressure measured within the subacromial space. Options to achieve such a difference can be increasing the arthroscopic pump pressure or hypotensive anesthesia, or a combination of both. Because excessive pump pressures can lead to complications related to fluid extravasa-

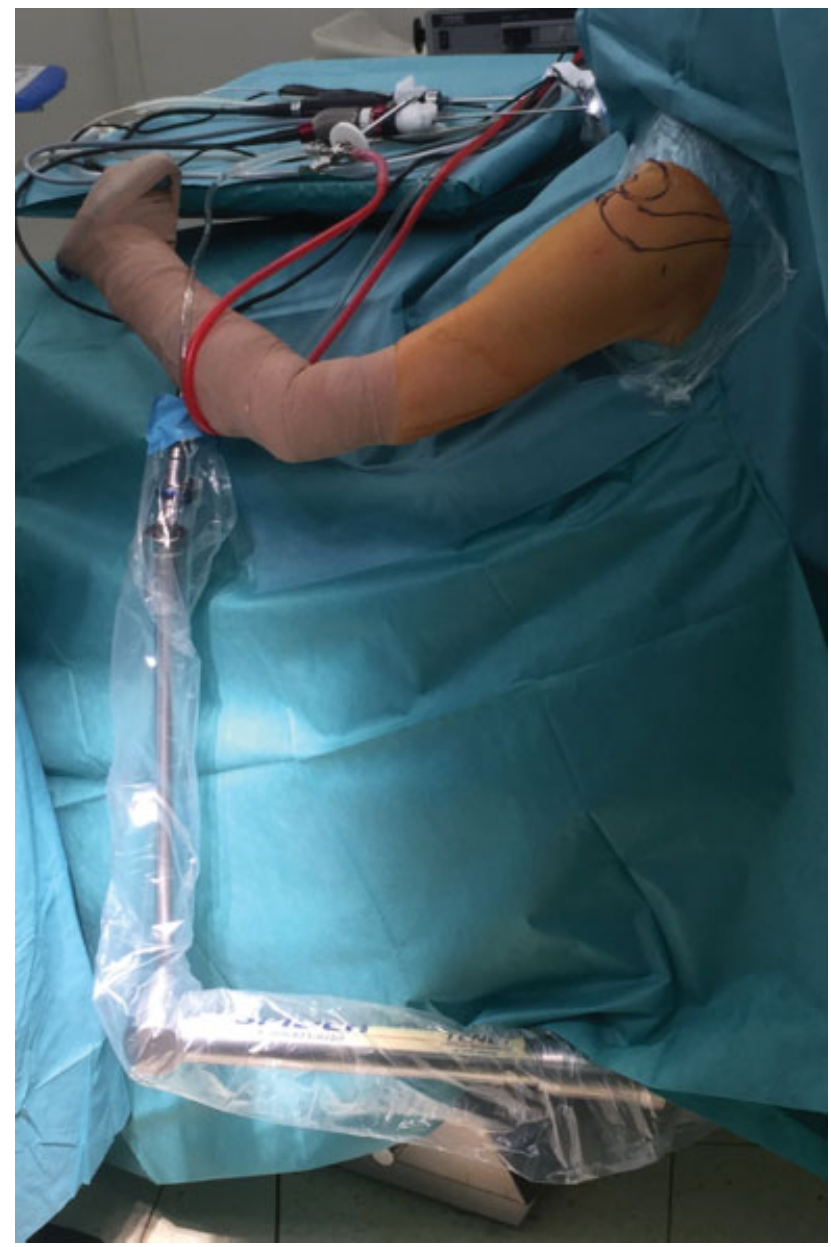

Fig. 3 Arm-positioner devices (e.g., Spider Limb Positioner, Smith and Nephew, Andover, Massachusetts, United States) may be either used for the lateral decubitus or beach chair position.

tion into the soft tissues, ${ }^{15-17}$ the use of deliberate hypotension in combination with modest elevation in pump pressure has been advocated as the optimum strategy. ${ }^{4,14}$

Another physiological change that may occur with the LD positioning is a pulmonary effect called ventilation-perfusion mismatch. ${ }^{18}$ Perfusion of the dependent lung usually increases, while ventilation decreases. In the nondependent lung, the opposite occurs with the ventilation increasing and the perfusion decreasing. This potentially can result in hypoxemia and should be considered when using the LD position in patients with reduced pulmonary reserve.

\section{LD Position Complications}

Fortunately, complications in shoulder arthroscopy in the LD are uncommon and many can be prevented with a careful patient positioning technique. These complications include neurovascular injuries, fluid-related obstructive airway compromise, and skin pressure-related issues.

\section{Neurovascular Injuries}

The most commonly reported complication in the $\mathrm{LD}$ position is neurological injury which can be due to excessive strain on the brachial plexus as a result of intraoperative traction, external nerve compression, or direct injury during the arthroscopic 
procedure. The reported incidence of transient paresthesia or nerve palsies after arthroscopic surgery in the LD has been reported to be $0.2 \%$ to $10 \%^{19-24}$ (-Table 2). Despite this relatively high incidence of nerve injuries, in almost all cases reported the injuries were neuropraxias and recovered in the reported cases. Andrews et $\mathrm{al}^{19}$ in a series of 120 patients who underwent shoulder arthroscopy in the LD position reported three cases of clinically important neuropraxia. The musculocutaneous nerve was involved in one patient and ulnar nerve in two patients. Ogilvie-Harris and Wile ${ }^{20}$ reported one case of musculocutaneous nerve palsy in 439 patients who underwent arthroscopic surgical procedures in the LD position. This injury resolved in approximately 6 weeks without any long-term sequelae. Berjano et al $^{22}$ reported three ulnar neurapraxias attributed to the use of a traction device in a series of 156 patients who underwent shoulder arthroscopy in the LD position. Similarly, Paulos and Franklin ${ }^{24}$ reported in a series of 76 patients, one case of axillary nerve neurapraxia with deltoid muscle dysfunction, which resolved after 2 months.

Pitman et al ${ }^{21}$ utilized somatosensory evoked potentials (SEP) to evaluate the onset of neurapraxia during shoulder arthroscopy performed in the LD position in 20 patients.

Results showed a $100 \%$ incidence of abnormal SEP of the musculocutaneous nerve, and $50 \%$ of patients also had varying combinations of involvement of the median, ulnar, and radial nerves. Fortunately, injury was subclinical in all but two patients $(10 \%)$ who had a neuropraxia which was transitory and recovered fully. Abnormal SEPs were related with the amount of weight used in the traction system. No abnormal SEP was found in any of the nerves of the brachial plexus with a weight lower than $12 \mathrm{lb}$. used for long-axis traction, and with a weight lower than $7 \mathrm{lb}$. used for perpendicular mid-humerus traction.

For the LD position, many traction devices involve a stocking or a device to hole the hand and where the traction is applied. As a result, compression of the digital nerves in the hand with subsequent neuropraxias has been reported. ${ }^{23}$ Ellman $^{23}$ reported three cases of transient dysesthesia of the dorsal digital nerve of the thumb believed to be due to poor padding of the extremity at the wrist.

In the LD position, brachial plexus palsy has also been reported to the nonoperative extremity closer to the bed. ${ }^{25}$ There has been only one report of a patient with a cervical rib who developed a transient C7-T1 contralateral neurapraxia after a shoulder arthroscopy in LD position. Although the presence of the cervical rib was suggested as the possible cause, use of a gel type of axillary roll between the chest and the bed is recommended to prevent these types of injuries to the nonoperative extremity

Neurovascular injuries seen in patients in the LD position may also be related with arthroscopic portal placement due to the patient being on their side. Only one cadaveric study has compared the risk of neurovascular injuries as they relate with the patient positioning. In that study, compared with the $\mathrm{BC}$ position, the LD position had an increased risk of injury to the musculocutaneous and axillary nerves when a 5 o'clock transubscapular or anteroinferior portal was utilized. ${ }^{9}$

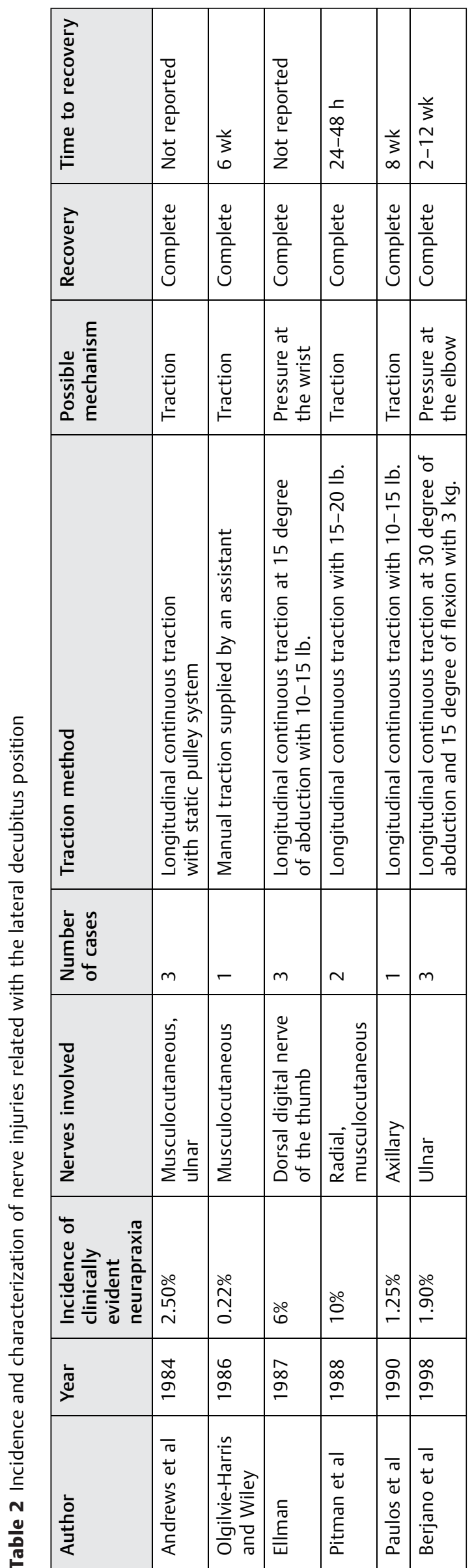


In addition to contribute to neuropraxias or skin problems, traction during shoulder arthroscopy with the patient in the LD position can cause a partial or complete tourniquet effect which could potentially impair the perfusion of the operative extremity. Hennrikus et $\mathrm{al}^{26}$ studied the effect of three methods of shoulder traction during arthroscopy on arterial oxygen saturation $\left(\mathrm{SaO}_{2}\right)$ measured by a pulse oximeter applied to the fingertip of the arm in traction of 30 patients. They found that simple longitudinal traction was the safest method in terms of limb's perfusion. Only 1 of 30 patients had decrease of the $\mathrm{SaO}_{2}$ with this method of traction. On the other hand, when perpendicular traction was applied with a narrow 2 -in sling, compression of the brachial artery by the sling caused decrease of the $\mathrm{SaO}_{2}$ in 25 of 30 limbs. The wider 4 -in sling used for perpendicular traction resulted in decrease of limb perfusion in only 7 of 30 patients and was found safer than the narrow sling.

\section{Fluid-related Obstructive Airway Compromise}

One concern with the LD position is accessibility to the airway should there be any airway compromise. In the limited cases reported, there were several potential causes of complete airway obstruction during shoulder arthroscopy in LD. ${ }^{15-17,27,28}$ Gravitational influence contributes to extravasated fluid-related airway compromise in the LD position. Risk factors which may contribute to this complication include protracted duration of procedure, arthroscopy in subacromial space (potential space with no encapsulation), increased pump pressure, large volume of irrigation fluid used and obesity. ${ }^{17}$ Although airway obstruction in those case reports has occurred both intraoperatively and postoperatively, endotracheal intubation has been suggested as the best way to maintain the airway and prevent airway compromise during arthroscopic shoulder surgery in the LD position.

\section{Pressure-Related Injuries}

In the LD position, direct pressure is applied to the contralateral half of the body which is in contact with the table. Routine procedures to protect the down hip and to protect the peroneal nerve are recommended. Keyurapan et $\mathrm{al}^{29}$ reported three patients $(0.3 \%)$ with severe pressure ulcerations to the dependent opposite thorax on a 10-year experience with 896 shoulder arthroscopy procedures in the LD position. Biopsy of the lesion in one patient was consistent with skin pressure ulceration. The exact cause of these lesions was deemed unknown by the authors, but the combination of the use of an intravenous fluid bag as an axillary roll, fluid between the skin and the roll, and friction from moving the patient were the contributing factors.

The peroneal nerve is subcutaneous at the fibular head on the contralateral leg and should be padded to prevent contact with the table or bean bag. Also, although it is a very uncommon injury, neuropraxia of the lateral femoral cutaneous nerve of the dependent extremity after shoulder arthroscopic surgery in the LD position has been reported. ${ }^{30}$

A summary of pearls and pitfalls of the LD position is provided in - Table 3 .

\section{Beach Chair Position}

The BC position, also referred to as the sitting position, was first developed on the east coast of the United States in the early 1980s as an alternative patient position to address the

Table 3 Pitfalls and pearls of the lateral decubitus position

\begin{tabular}{|c|c|}
\hline Pitfall & Pearls \\
\hline $\begin{array}{l}\text { Neurological } \\
\text { injuries }\end{array}$ & $\begin{array}{l}\text { - The safest traction method that would maximize visibility while minimizing strain to the nerves and } \\
\text { detriment to the perfusion of the limb is the traction parallel to the long axis of the arm }{ }^{26} \text { with less than } 12 \\
\mathrm{lb}{ }^{21} \text { in any of two positions: } 45 \text { degree of forward flexion and } 90 \text { degree of abduction or } 45 \text { degree of } \\
\text { forward flexion and } 0 \text { degree of abduction. } 59 \\
\text { - Another method of traction is the lateral traction to the mid-humerus perpendicular to the axis of the arm. } \\
\text { While the risk of neurapraxia has been reported as inexistent with this method of traction, }{ }^{10} \text { there is a } \\
\text { demonstrated detrimental effect in the perfusion of the arm from the constriction of the sling. }{ }^{26} \text { Therefore } \\
\text { the use of a wide } 4 \text {-in sling to decrease the tourniquet effect }{ }^{26} \text { with less than } 7 \text { lb. of weight traction to avoid } \\
\text { strain to the nerves }{ }^{21} \text { is recommended. } \\
\text { - When wrapping the traction system avoid direct pressure over bony prominences (wrist and elbow). } \\
\text { - Additional care and counseling must be taken with patients with cervical ribs for the rare but possible risk of } \\
\text { contralateral brachial plexus compression. }\end{array}$ \\
\hline $\begin{array}{l}\text { Airway } \\
\text { obstruction }\end{array}$ & $\begin{array}{l}\text { - Minimize arthroscopic pump pressures. } \\
\text { - Use of deliberate hypotensive anesthesia in selected patients. } \\
\text { - Limit the amount of irrigation fluid. } \\
\text { - Restrict surgical time. } \\
\text { - Longer cases should be performed under general anesthesia so that adequate control over airway is ensured. }\end{array}$ \\
\hline $\begin{array}{l}\text { Pressure- } \\
\text { related } \\
\text { injuries }\end{array}$ & $\begin{array}{l}\text { - Pay attention to the detail in padding and positioning patients. } \\
\text { - Check bony prominences, areola, and genitals for undue pressure zones. } \\
\text { - Careful padding of contralateral arm and knees (special care to the lateral side of the dependent } \\
\text { knee/common peroneal nerve). } \\
\text { - Proper axillary roll position optimizes ventilation while preventing brachial plexus compression injury. }{ }^{60} \\
\text { - Caxillary roll: not directly in the axilla. If possible, avoid the use of bags of fluids to make the axillary roll. } \\
\text { - Carry out frequent evaluation of patient positioning and padding. }\end{array}$ \\
\hline
\end{tabular}


issue of brachial plexus traction injuries experienced by patients in the $\mathrm{LD}$ position. ${ }^{1}$ Another advantage of the $\mathrm{BC}$ was that the arm was not in a fixed position as in LD but could be moved into a variety of positions. ${ }^{31}$ In 1988 , Skyhar et al ${ }^{31}$ was the first to describe the experience with arthroscopic shoulder surgery performed in 50 patients in the $\mathrm{BC}$ position sitting up at a minimum of 60 degree. The authors reported that this position provided excellent visualization of the joint without any complications. This position gained popularity in the United States and today approximately two-thirds of the arthroscopic shoulder procedures are performed with the patient in the $\mathrm{BC}$ position. ${ }^{32}$ The main advantages of the BC position include: (1) a decreased risk of neurovascular complications in the operative extremity as traction is not needed, ${ }^{31}$ (2) an "anatomical" view of the joint that might result in an easier orientation and understanding of the shoulder anatomy for surgical trainees, ${ }^{1,3,31}$ (3) easier humeral rotation and translation control, ${ }^{33}(4)$ easier conversion to an open procedure, ${ }^{31}$ (5) flexibility of choosing general or regional anesthesia, and (6) easier access to the airway if complications arise. ${ }^{3}$

Advocates of the $\mathrm{BC}$ position argue that $\mathrm{BC}$ allows increased access to the anterior, posterior, and superior glenohumeral joint and to the subacromial space. ${ }^{31}$ Other technical advantages are easier examination under anesthesia of the operative arm as it can be dynamically evaluated. Also the $\mathrm{BC}$ is suggested to have easier access to the anterior portal as the arm is not on the way. ${ }^{1}$

While there are purportedly many advantages of the BC position, there are some disadvantages which must be considered in some patients. The main disadvantage of the $\mathrm{BC}$ position is its physiological effect on the cardiovascular system. With the patient sitting essentially upright, there is a higher rate of hypotensive and bradycardic events. This can lead to cerebral hypoperfusion and may result in strokes and in some cases death. ${ }^{34}$ Though the risk of a cerebrovascular event during shoulder surgery in the $\mathrm{BC}$ position is extremely rare, its complications can be catastrophic. ${ }^{30,34-36}$ Other disadvantages include: (1) camera view may be obscured due to fluid causing fog on the camera or cautery bubbles in the subacromial space, ${ }^{1,37}(2)$ there is a theoretically increased risk of air embolus, ${ }^{1}$ (3) there is a limited access to the posterior and posterior-inferior aspects of the joint, ${ }^{37,38}$ and (4) the setup may be expensive if specialized headrest (i.e., BC attachments) and arm-positioners are utilized. ${ }^{3}$

\section{BC Position Setup}

A summary of key steps for LD patient positioning is provided in -Table 4.

As described in the original paper by Skyhar et al, ${ }^{31}$ the $\mathrm{BC}$ position may be successfully accomplished with a standard operating table. Currently, there are several commercially available BC attachments with specialized headrest devices (e.g., Ultra Shoulder Positioner, Mizuho OSI, Union City, California, United States or Lift-Assist Beach Chair Positioning, Arthrex, Naples, Florida, United States) and mechanical or pneumatical arm-positioners such as the Trimano Fortis (Arthrex, Naples, Florida, United States) or the Spider 2 Limb
Table 4 Key steps for patient positioning in the beach chair position

1. Plan and anticipate patient challenges.

2. Stratify patients for the risk of cerebral desaturation events in the BC position (-Table $\mathbf{5}$ ).

3. Check that the break of the table is at the level of patient's greater trochanter prior to rise the back of the table up.

4. Raise the back of the table up between 30 and 60 degree. The use of a more upright position (80 to 90 degree $)^{8}$ might improve the access to the posteroinferior shoulder and an easier orientation of the anatomy.

5. Closer monitoring of the blood pressure and cerebral saturation is required during and after positioning the patient.

6. If a traditional table is utilized shift the patient toward the operative side so the medial border of their scapula is just at the edge of the bed.

7. Make sure that an adequate access to the operative field and a satisfactory mobility of the operative arm are achieved.

8. Place a large pad or several pillows underneath the patient's legs.

9. Secure the nonoperative arm to the patient's abdomen or on a padded arm board.

10. Secure the patient's head and neck. Regardless of the method utilized to secure the head, ensure a neutral position.

11. If an arm-positioning device is used, care must be taken when applying the traction to the arm.

12. Secure the patient to the table with a security strap. Avoid direct pressure by the strap on bony prominences or the skin.

13. Check the patient's position frequently during surgery securing a neutral head alignment.

Positioner (Smith and Nephew, Andover, Massachusetts, United States) (- Fig. 3). While these devices add ease to the positioning and to the procedure, they increase the cost of the setup and they are not an absolute necessity to accomplish a safe and successful arthroscopic procedure in the BC position.

\section{BC Position Physiological Effects}

Cardiovascular changes are the most important physiological effect of the $\mathrm{BC}$ position. In the normal physiological state, the sympathetic nervous system is activated when assuming the seated position. This results in increased systemic vascular resistance and heart rate alterations to maintain mean arterial pressure. Conversely, under general anesthesia the autonomic nervous system response is blunted by the vasodilating effects of anesthetics, resulting in decreased cardiac output, decreased mean arterial pressure, and subsequent cerebral hypoperfusion. ${ }^{39}$ These changes can lead to detectable intraoperative cerebral desaturation events (CDEs) seen in as many of $80 \%$ of the patients as measured with near infrared spectroscopy. ${ }^{6,7,40-42}$ These desaturation events typically can potentially lead to cerebral ischemia.

The precise pathophysiology of the ischemic neurological events remains unclear. Some investigators suggest that the relationship between desaturation events and cerebral ischemia is related to the patient-specific risk factors such as 
congenital anomalies of cerebral circulation. ${ }^{40}$ Patients may be at increased risk without any knowledge as congenital variations of the circle of Willis anatomy have been described in 59 to $79 \%$ of the adults. ${ }^{43,44}$

Besides the possible correlation with ischemic cerebrovascular events, CDEs might be correlated with neurocognitive abnormalities after surgery ${ }^{41}$. Studies that have assessed the clinical implications of CDEs in patients undergoing shoulder arthroscopic surgeries in the BC position are inconclusive. $^{42,45}$ The degree and duration of cerebral ischemia required to produce neurocognitive dysfunction in this population remain unidentified. ${ }^{45}$

The incidence of CDEs in shoulder arthroscopic procedures in the $\mathrm{BC}$ position has been associated with the type of anesthesia. CDEs in the $\mathrm{BC}$ position may be less likely during regional anesthesia compared with general anesthesia. In a prospective comparative study, Koh et al $^{40}$ compared the rate of CDEs of awake patients when procedures were performed in the $\mathrm{BC}$ position compared with patients under general anesthesia. A higher incidence of CDEs was seen in the asleep group ( 56.7 vs. $0 \%$ awake group), and more CDEs were seen per patient ( 2.97 in asleep vs. 0 awake, $p<0.0001)$. The reasons for less cerebral desaturation with regional anesthesia are unclear but may include better preservation of blood pressure and higher partial pressure of carbon dioxide $\left(\mathrm{PaCO}_{2}\right)$ during regional anesthesia.

\section{BC Position Complications}

Shoulder arthroscopy in the BC position is generally safe with a low rate of complications. Complications are very rare and may be prevented with adequate planning and positioning technique. A summary of pearls and pitfalls of the LD position is provided in - Table 5 .

\section{Neurological Injuries}

Neurological complications are the most common and devastating complications in the $\mathrm{BC}$. They can be roughly categorized as cerebrovascular events and peripheral compression nerve injuries resulting from patient positioning.

\section{Cerebrovascular Events}

Friedman et $\mathrm{al}^{32}$ surveyed American shoulder surgeons, who had performed over 200,000 shoulder procedures in the BC position, mostly arthroscopic, and found eight incidences of cerebrovascular events, for an overall incidence of $0.003 \%$. Despite this very low incidence, the neurological sequelae can be devastating for the patient, the family, and the providers. Pohl and Cullen ${ }^{34}$ reported four cases of ischemic brain injury after shoulder surgery in the $\mathrm{BC}$ position that resulted in death in one patient and severe brain damage in three patients. Drummond et $\mathrm{al}^{30}$ reported one case of stroke and right hemiparesis after shoulder surgery in the $\mathrm{BC}$ position in a patient with a congenital variation of circle of Willis anatomy. Visual loss and ophthalmoplegia have also been described after shoulder surgery in the $\mathrm{BC}$ position. ${ }^{35,36}$ While the exact pathophysiology of these cerebrovascular events is not well understood, strategies to decrease hypotensive/bradycardic events and CDEs are warranted. As outlined above, regional anesthesia has proven to decrease the rate of CDEs compared with general anesthesia when procedures are performed in the BC position. ${ }^{40}$ Similarly, in a randomized controlled trial Chierichini et $\mathrm{al}^{46}$ reported that the use of norepinephrine

Table 5 Pitfall and pearls of the beach chair position

\begin{tabular}{|c|c|}
\hline Pitfall & Pearls \\
\hline $\begin{array}{l}\text { Cerebrovascular } \\
\text { events }\end{array}$ & $\begin{array}{l}\text { - Stratify patients for the risk of cerebral desaturation events in the BC position. } \\
\text { o High risk: obese patients (BMI > } 34) .45 \\
\text { o Possible risk: diabetes mellitus, obstructive sleep apnea, hypertension, older patients with more medical } \\
\text { comorbidities, and history of stroke. } 7,45,61 \\
\text { - Consider the use of isolated regional anesthesia. The use of regional anesthesia under an interscalene } \\
\text { block and sedation may be the most effective strategy to decrease the risk of CDE and ischemic } \\
\text { neurological injury in the BC position. }{ }^{40,41} \\
\text { - When general anesthesia is preferable or unavoidable, noninvasive monitoring of regional cerebral } \\
\text { oxygenation with near-infrared spectroscopy is recommended. }{ }^{40} \\
\text { - Consider the use of a less upright position ( } 30 \text { degree to } 45 \text { degree) for patients with a high or probable } \\
\text { risk of CDE ( - Fig. } 4) \text {. A linear relationship between the angle of the BC position and an increase of cerebral } \\
\text { deoxygenation has been demonstrated. }{ }^{61} \\
\text { - If a vasopressor agent is planned to be used in the irrigation fluid to decrease the intraoperative bleeding, } \\
\text { consider the use of norepinephrine ( } 0.66 \text { mg/L) rather than epinephrine. }{ }^{46} \\
\text { - Keep an open communication with the anesthesia team of cardiovascular changes and cerebral } \\
\text { oxygenation during patient positioning and during the procedure. }\end{array}$ \\
\hline $\begin{array}{l}\text { Peripheral } \\
\text { neurological } \\
\text { injuries }\end{array}$ & $\begin{array}{l}\text { - Head and neck should be neutral. Avoid flexion, hyperextension, or lateral flexion. } \\
\text { - Head position should be checked frequently during shoulder surgery especially if the angle of the } \\
\text { operating table is changed. }{ }^{48} \\
\text { - Protect the auricle against compression with extra padding of the headrest to minimize pressure. } \\
\text { - Careful attention to placing the security belt across the thighs, rather than higher up around the waist, } \\
\text { may avoid compression of the lateral femoral cutaneous nerve (LFCN). }{ }^{62} \\
\text { - Limiting hip flexion by using reverse Trendelenburg to maintain a modified beach chair position may } \\
\text { minimize compression of the LFCN from the belt. }{ }^{6} \\
\text { - Proper preoperative counseling to obese patients with a BMI }>34 \text { of possible LFCN neurapraxia. }{ }^{47}\end{array}$ \\
\hline
\end{tabular}




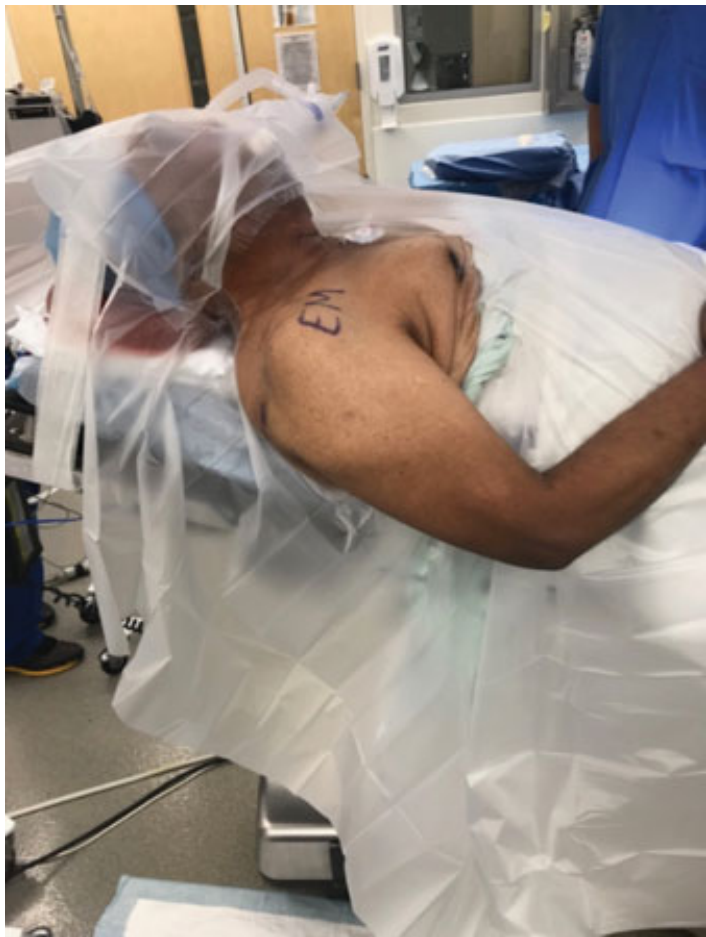

Fig. 4 Patient in the beach chair position in a less upright position (30 degree).

diluted in irrigation fluid during arthroscopic rotator cuff repair with the patient in the $\mathrm{BC}$ position reduces the incidence of hypotensive/bradycardic events and is as effective as epinephrine in maintaining the visual clarity of the surgical field.

\section{Peripheral Compression Nerve Injuries}

Other neurological injuries reported in the literature with the $\mathrm{BC}$ position are direct external nerve compressions which are probably related to patient positioning.

Lateral femoral cutaneous nerve palsy after shoulder surgery in the BC position is an uncommon complication, with a calculated prevalence of $1.3 \% .{ }^{47}$ Patient BMI and body weight were found risk factors for its development. Other potential factors contributing to the development of lateral femoral cutaneous nerve palsy include the positioning and tightness of the restraining belt.

Cogan et $\mathrm{al}^{48}$ and Boisseau et $\mathrm{al}^{49}$ reported two cases of neuropraxia of the ninth, tenth, and twelfth cranial nerve pairs after arthroscopic rotator cuff repair in the BC position. Although cerebral hypoperfusion was considered as a possible cause, the most likely hypothesis proposed by those authors was that there was potentially a mechanical, extracranial cause. During surgery any change in position which modifies the angle of the trunk in relation to the headrest, can potentially cause nerve compression under the angle of the jaw. ${ }^{48}$ Similarly, there have been five reported cases of isolated hypoglossal nerve neurapraxia reported in the literature in patients undergoing shoulder surgery in the BC position. While the exact mechanism is unknown, either compression or distraction of the nerve may be involved. ${ }^{50-54}$ Eight cases of neurapraxia of the greater auricular nerve have been reported in the literature after shoulder surgery in the $\mathrm{BC}$ position, and direct nerve compression by the headrest was considered to be the etiology. ${ }^{55-58}$

\section{Conclusion}

Overall, the BC and the LD positions are safe and successful methods for patient positioning in shoulder arthroscopic procedures without conclusive evidence of superiority of one position to the other. Each position offers advantages and disadvantages and surgeon's experience and training are pivotal when selecting one position versus another. Complications are very rare with both positions and most of them are avoidable.

To minimize complications and improve patient counseling, surgeons and their teams must understand the technique, physiological changes, and possible complications of the positioning method adopted in their practices. In the LD position, efforts must be directed to avoid neurological injuries related with the traction system, pressure injuries related with the position, and potential airway obstruction. In the $\mathrm{BC}$ position, strategies to decrease complications are the patient stratification of risk for cerebral desaturation events, careful monitoring of the cardiovascular changes, and cerebral oxygenation and an adequate positioning of the head and neck.

Funding

None.

Conflict of Interest

None declared.

\section{References}

1 Li X, Eichinger JK, Hartshorn T, Zhou H, Matzkin EG, Warner JP. A comparison of the lateral decubitus and beach-chair positions for shoulder surgery: advantages and complications. J Am Acad Orthop Surg 2015;23(01):18-28

2 Association of Surgical Technologists. Guidelines for Surgical Positioning. Available at: http://www.ast.org. Accessed September 1, 2019

3 Peruto CM, Ciccotti MG, Cohen SB. Shoulder arthroscopy positioning: lateral decubitus versus beach chair. Arthroscopy 2009; 25(08):891-896

4 Rains DD, Rooke GA, Wahl CJ. Pathomechanisms and complications related to patient positioning and anesthesia during shoulder arthroscopy. Arthroscopy 2011;27(04):532-541

5 Hamamoto JT, Frank RM, Higgins JD, Provencher MT, Romeo AA, Verma NN. Shoulder arthroscopy in the lateral decubitus position. Arthrosc Tech 2017;6(04):e1169-e1175

6 Murphy GS, Szokol JW, Marymont JH, et al. Cerebral oxygen desaturation events assessed by near-infrared spectroscopy during shoulder arthroscopy in the beach chair and lateral decubitus positions. Anesth Analg 2010;111(02):496-505

7 Pant S, Bokor DJ, Low AK. Cerebral oxygenation using nearinfrared spectroscopy in the beach-chair position during shoulder arthroscopy under general anesthesia. Arthroscopy 2014;30(11): $1520-1527$

8 Selby R. Setup and patient positioning. In: Angelo RL, Esch J, Ryu RKN, eds. AANA Advanced Arthroscopy. The Shoulder. Philadelphia, PA: Saunders/Elsevier; 2010:53-58 
9 Gelber PE, Reina F, Caceres E, Monllau JC. A comparison of risk between the lateral decubitus and the beach-chair position when establishing an anteroinferior shoulder portal: a cadaveric study. Arthroscopy 2007;23(05):522-528

10 Gross RM, Fitzgibbons TC. Shoulder arthroscopy: a modified approach. Arthroscopy 1985;1(03):156-159

11 Yokoyama M, Ueda W, Hirakawa M. Haemodynamic effects of the lateral decubitus position and the kidney rest lateral decubitus position during anaesthesia. Br J Anaesth 2000;84(06):753-757

12 Thompson GE, Miller RD, Stevens WC, Murray WR. Hypotensive anesthesia for total hip arthroplasty: a study of blood loss and organ function (brain, heart, liver, and kidney). Anesthesiology 1978;48(02):91-96

13 Tuncali B, Karci A, Bacakoglu AK, Tuncali BE, Ekin A. Controlled hypotension and minimal inflation pressure: a new approach for pneumatic tourniquet application in upper limb surgery. Anesth Analg 2003;97(05):1529-1532

14 Morrison DS, Schaefer RK, Friedman RL. The relationship between subacromial space pressure, blood pressure, and visual clarity during arthroscopic subacromial decompression. Arthroscopy 1995;11(05):557-560

15 Blumenthal S, Nadig M, Gerber C, Borgeat A. Severe airway obstruction during arthroscopic shoulder surgery. Anesthesiology 2003;99(06):1455-1456

16 Antonucci S, Orlandi P, Mattei PA, Amato F. Airway obstruction during arthroscopic shoulder surgery: anesthesia for the patient or for the surgeon? Minerva Anestesiol 2006;72(12):995-1000

17 Hynson JM, Tung A, Guevara JE, Katz JA, Glick JM, Shapiro WA. Complete airway obstruction during arthroscopic shoulder surgery. Anesth Analg 1993;76(04):875-878

18 Larsson A, Malmkvist G, Werner O. Variations in lung volume and compliance during pulmonary surgery. Br J Anaesth 1987;59(05): 585-591

19 Andrews JR, Carson WG Jr, Ortega K. Arthroscopy of the shoulder: technique and normal anatomy. Am J Sports Med 1984;12(01):1-7

20 Ogilvie-Harris DJ, Wiley AM. Arthroscopic surgery of the shoulder. A general appraisal. J Bone Joint Surg Br 1986;68(02): 201-207

21 Pitman MI, Nainzadeh N, Ergas E, Springer S. The use of somatosensory evoked potentials for detection of neuropraxia during shoulder arthroscopy. Arthroscopy 1988;4(04):250-255

22 Berjano P, González BG, Olmedo JF, Perez-España LA, Munilla MG. Complications in arthroscopic shoulder surgery. Arthroscopy 1998;14(08):785-788

23 Ellman H. Arthroscopic subacromial decompression: analysis of one-to three-year results. Arthroscopy 1987;3(03):173-181

24 Paulos LE, Franklin JL. Arthroscopic shoulder decompression development and application. A five year experience. Am J Sports Med 1990;18(03):235-244

25 Pavlik A, Ang KC, Bell SN. Contralateral brachial plexus neuropathy after arthroscopic shoulder surgery. Arthroscopy 2002;18 (06):658-659

26 Hennrikus WL, Mapes RC, Bratton MW, Lapoint JM. Lateral traction during shoulder arthroscopy: its effect on tissue perfusion measured by pulse oximetry. Am J Sports Med 1995;23(04): 444-446

27 Yoshimura E, Yano T, Ichinose K, Ushijima K. Airway obstruction involving a laryngeal mask airway during arthroscopic shoulder surgery. J Anesth 2005;19(04):325-327

28 No MY, Kim PO, Choi WJ. Airway compression after arthroscopic shoulder surgery under general anesthesia. Korean J Anesthesiol 2013;65(6, Suppl):S121-S122

29 Keyurapan E, Hu SJ, Redett R, McCarthy EF, McFarland EG. Pressure ulcers of the thorax after shoulder surgery. Knee Surg Sports Traumatol Arthrosc 2007;15(12):1489-1493

30 Drummond JC, Lee RR, Howell JP Jr. Focal cerebral ischemia after surgery in the "beach chair" position: the role of a congenital variation of circle of Willis anatomy. Anesth Analg 2012;114(06): 1301-1303

31 Skyhar MJ, Altchek DW, Warren RF, Wickiewicz TL, O'Brien SJ Shoulder arthroscopy with the patient in the beach-chair position. Arthroscopy 1988;4(04):256-259

32 Friedman DJ, Parnes NZ, Zimmer Z, Higgins LD, Warner JJP. Prevalence of cerebrovascular events during shoulder surgery and association with patient position. Orthopedics 2009;32(04):1-5

33 Terry M, Altchek DW. Diagnostic shoulder arthroscopy technique: beach chair position. In: Tibone JE, Savoie FH, Shaffer BS, eds. Shoulder Arthroscopy. New York, NY: Springer-Verlag; 2003:9-15

34 Pohl A, Cullen DJ. Cerebral ischemia during shoulder surgery in the upright position: a case series. J Clin Anesth 2005;17(06): 463-469

35 Bhatti MT, Enneking FK. Visual loss and ophthalmoplegia after shoulder surgery. Anesth Analg 2003;96(03):899-902

36 Mumith A, Scadden J. Postoperative vision loss after reverse shoulder arthroplasty. Case Rep Orthop 2014;2014:850950

37 Higgins JD, Frank RM, Hamamoto JT, Provencher MT, Romeo AA, Verma NN. Shoulder arthroscopy in the beach chair position. Arthrosc Tech 2017;6(04):e1153-e1158

38 Jinnah AH, Mannava S, Plate JF, Stone AV, Freehill MT. Basic shoulder arthroscopy: lateral decubitus patient positioning. Arthrosc Tech 2016;5(05):e1069-e1075

39 Smelt WL, de Lange JJ, Booij LH. Cardiorespiratory effects of the sitting position in neurosurgery. Acta Anaesthesiol Belg 1988;39 (04):223-231

40 Koh JL, Levin SD, Chehab EL, Murphy GS. Neer Award 2012: cerebral oxygenation in the beach chair position: a prospective study on the effect of general anesthesia compared with regional anesthesia and sedation. J Shoulder Elbow Surg 2013;22(10):1325-1331

41 Aguirre JA, Märzendorfer O, Brada M, Saporito A, Borgeat A, Bühler P. Cerebral oxygenation in the beach chair position for shoulder surgery in regional anesthesia: impact on cerebral blood flow and neurobehavioral outcome. J Clin Anesth 2016;35:456-464

42 Laflam A, Joshi B, Brady K, et al. Shoulder surgery in the beach chair position is associated with diminished cerebral autoregulation but no differences in postoperative cognition or brain injury biomarker levels compared with supine positioning: the anesthesia patient safety foundation beach chair study. Anesth Analg 2015;120(01):176-185

43 van Raamt AF, Mali WPTM, van Laar PJ, van der Graaf Y. The fetal variant of the circle of Willis and its influence on the cerebral collateral circulation. Cerebrovasc Dis 2006;22(04):217-224

44 Manninen H, Mäkinen K, Vanninen R, Ronkainen A, Tulla H. How often does an incomplete circle of Willis predispose to cerebral ischemia during closure of carotid artery? Postmortem and clinical imaging studies. Acta Neurochir (Wien) 2009;151(09): 1099-1105

45 Salazar D, Sears BW, Aghdasi B, et al. Cerebral desaturation events during shoulder arthroscopy in the beach chair position: patient risk factors and neurocognitive effects. J Shoulder Elbow Surg 2013;22(09):1228-1235

46 Chierichini A, Frassanito L, Vergari A, et al. The effect of norepinephrine versus epinephrine in irrigation fluid on the incidence of hypotensive/bradycardic events during arthroscopic rotator cuff repair with interscalene block in the sitting position. Arthroscopy 2015;31(05):800-806

47 Holtzman AJ, Glezos CD, Feit EJ, Gruson KI. Prevalence and risk factors for lateral femoral cutaneous nerve palsy in the beach chair position. Arthroscopy 2017;33(11):1958-1962

48 Cogan A, Boyer P, Soubeyrand M, Hamida FB, Vannier JL, Massin P. Cranial nerves neuropraxia after shoulder arthroscopy in beach chair position. Orthop Traumatol Surg Res 2011;97(03):345-348

49 Boisseau N, Rabarijaona H, Grimaud D, Raucoules-Aim M. Tapia's syndrome following shoulder surgery. $\mathrm{Br} \mathrm{J}$ Anaesth 2002; 88:869-870 
50 Mullins RC, Drez D Jr, Cooper J. Hypoglossal nerve palsy after arthroscopy of the shoulder and open operation with the patient in the beach-chair position. A case report. J Bone Joint Surg Am 1992;74(01):137-139

51 Choi WJ, Shin HK, Kim DO, Park SW, Lee DI, Kim DS. Transient hypoglossal nerve palsy after general anesthesia in beach chair position for shoulder arthroscopic Bankart repair: a case report. Korean J Anesthesiol 2004;47(02):277-280

52 Hung NK, Lee $\mathrm{CH}$, Chan SM, et al. Transient unilateral hypoglossal nerve palsy after orotracheal intubation for general anesthesia. Acta Anaesthesiol Taiwan 2009;47(01):48-50

53 Rhee YG, Cho NS. Isolated unilateral hypoglossal nerve palsy after shoulder surgery in beach-chair position. J Shoulder Elbow Surg 2008;17(04):e28-e30

54 Kim CJ, Oh HS, Park J, Chung MY. Cranial nerve XII (hypoglossal nerve) palsy after arthroscopic shoulder surgery under general anesthesia combined with sono-guided interscalene brachial plexus block: a case report. Anesth Pain Med 2016;11(03): 322-325

55 Park TS, Kim YS. Neuropraxia of the cutaneous nerve of the cervical plexus after shoulder arthroscopy. Arthroscopy 2005; 21(05):631
56 Joshi M, Cheng R, Kamath H, Yarmush J. Great auricular neuropraxia with beach chair position. Local Reg Anesth 2017;10:75-77

$57 \mathrm{Ng}$ AKH, Page RS. Greater auricular nerve neuropraxia with beach chair positioning during shoulder surgery. Int J Shoulder Surg 2010;4(02):48-50

58 LaPrade CM, Foad A. Greater auricular nerve palsy after arthroscopic anterior-inferior and posterior-inferior labral tear repair using beach-chair positioning and a standard universal headrest. Am J Orthop 2015;44(04):188-191

59 Klein AH, France JC, Mutschler TA, Fu FH. Measurement of brachial plexus strain in arthroscopy of the shoulder. Arthroscopy 1987;3 (01):45-52

60 Bonnaig N, Dailey S, Archdeacon M. Proper patient positioning and complication prevention in orthopaedic surgery. J Bone Joint Surg Am 2014;96(13):1135-1140

61 Songy CE, Siegel ER, Stevens M, Wilkinson JT, Ahmadi S. The effect of the beach-chair position angle on cerebral oxygenation during shoulder surgery. J Shoulder Elbow Surg 2017;26(09):1670-1675

62 Feldman MD. Editorial commentary: my shoulder feels great, but why is my thigh numb? Lateral femoral cutaneous nerve injury after shoulder arthroscopy in the beach chair position. Arthroscopy 2017;33(11):1963-1964 